\title{
EDUCAÇÃO PELO TRABALHO PARA A FORMAÇÃO DO MÉDICO
}

\author{
EDUCATION THROUGH WORK FOR THE TRAINING OF A PHYSICIAN
}

\author{
Guilherme Souza Cavalcanti de Albuquerque ${ }^{1}$ \\ Ana Áurea Revoredo Torres ${ }^{2}$ \\ Bárbara do Nascimento ${ }^{3}$ \\ Beatris Mario Martin ${ }^{4}$ \\ Diego Fabian Karvat Gracia ${ }^{5}$ \\ Juliana Myriam Machado Orlando ${ }^{6}$ \\ Rodrigo Pirard Basso ${ }^{7}$ \\ Paulo de Oliveira Perna ${ }^{8}$
}

Resumo O Programa de Educação pelo Trabalho para a Saúde (PET-Saúde) visa qualificar a força de trabalho para o Sistema Único de Saúde. O presente estudo foi desenvolvido com o objetivo de avaliar a contribuição de três experiências do PET-Saúde para a formação médica. Com base no materialismo histórico-dialético, buscou-se compreender a inserção do PET-Saúde na educação médica como fenômeno social subordinado às condições históricas de produção econômica. Os dados foram colhidos de relatos dos estudantes, tutores, preceptores e coordenadores de três grupos do PET-Saúde de duas universidades de Curitiba, por meio de entrevistas e grupos focais. Concluiu-se que, em dois grupos, as experiências vivenciadas contribuíram para a formação de trabalhadores flexíveis, efetivos na aplicação da tecnologia para a solução dos problemas nos limites impostos pela ordem vigente. No terceiro grupo, a experiência contribuiu para a formação de sujeitos críticos, capazes de questionar os limites impostos pelo Estado e pela sociedade à plena realização da vida.

Palavras-chave formação médica; PET-Saúde; educação pelo trabalho.
Abstract The Education Through Work for Health Program (PET-Saúde) aims to qualify the workforce for the Brazilian Unified Health System. This study was carried out to evaluate the contribution made by three PET-Saúde experiments in medical training. Based on historical and dialectical materialism, we sought to understand the integration of PET-Saúde in medical education as a social phenomenon subordinate to the historical conditions of economic production. Data were collected from reports made by students, tutors, mentors and coordinators of three groups of PET-Saúde at two universities in Curitiba, southern Brazil, through interviews and focus groups. It was concluded that, in two groups, the experiences contributed to training flexible workers, effective in the application of technology to solve issues within the limits imposed by the current order. In the third group, the experience contributed to training critical subjects, able to question the limits imposed by the State and society to the full realization of life.

Keywords medical training; PET-Saúde, education for work. 


\section{Introdução}

A defesa da necessidade da mudança no ensino médico como consequência das transições demográfica e epidemiológica, além do avanço tecnológico da medicina, tem-se apresentado com crescente vigor. Argumenta-se que para realizar a medicina atual é preciso também atualizar a formação médica.

No Brasil, a criação do Sistema Único de Saúde (SUS) representou a possibilidade de uma medicina mais voltada para a preservação da saúde e sua recuperação, com o uso de tecnologias mais leves, para o que seria necessária a adequação da formação médica. Com isso, um grande movimento de reforma passou a ser impulsionado visando à mudança na formação médica a fim de adequá-la às 'novas necessidades da sociedade'. Nesse sentido, a instituição das Diretrizes Curriculares Nacionais do Curso de Graduação em Medicina constituiu passo fundamental. Essas diretrizes definem o perfil do egresso, suas habilidades e atitudes; preconizam uma pedagogia ativa, centrada no aluno; tensionam a formação de modo a adequá-la às necessidades locais de saúde, visando a um profissional com uma formação geral, por meio da aprendizagem em novos cenários (Brasil, 2001).

O Estado brasileiro tem investido persistentemente na ideia da formação desse novo tipo de profissional de saúde. Nesse sentido, o Ministério da Saúde tem financiado programas e ações como o Programa de Educação pelo Trabalho para a Saúde (PET-Saúde), no sentido de: “Ampliar e qualificar a força de trabalho em saúde, caracterizando-a como um investimento essencial para a perspectiva de evolução do SUS" (Brasil, 2008, p. 59). Para isso, estimula a inserção precoce dos estudantes na atenção básica a fim de que usufruam desse meio como cenário de aprendizagem.

Entendendo a necessidade de permanente atualização da formação médica, mas consciente do risco de prejuízo da mesma diante da imposição de atender às necessidades do capital, frequentemente opostas às da classe trabalhadora, desenvolveu-se o presente estudo, cujo objetivo é avaliar as potencialidades e limitações de três experiências do PET-Saúde para a formação médica.

\section{Origem das mudanças na formação médica}

As ideias sobre as quais se assentam as mudanças na educação têm forte nexo com o ideário pós-moderno, ${ }^{9}$ fundamento ideológico do neoliberalismo. No movimento de atualização das formas de exploração da força de trabalho pelo capital, advoga-se a necessidade de rever o papel da educação na reprodução da força de trabalho. Diante da intensificação da substituição do trabalho vivo por trabalho morto, 10 e consequente simplificação do trabalho e desqualificação 
do trabalhador necessário (Alves, 1998, p. 119), intensifica-se a possibilidade da redução do custo de reprodução da força de trabalho, necessidade permanente do capital. Nesse sentido, o custo da formação do médico compõe tanto o custo da reprodução da força de trabalho médica quanto o custo da reprodução da força de trabalho em geral, motivo pelo qual esse custo precisa ser permanentemente reduzido, viabilizando o aumento da mais-valia relativa (Albuquerque, 2009).

Além disso, a substituição do trabalho vivo por trabalho morto cria não somente um exército de reserva, 11 mas também uma parcela crescente de população sobrante12 (Frigotto, 1999), pois o incremento da produtividade mediante a substituição do trabalho vivo por trabalho morto torna desnecessária para o capital a reprodução da vida de significativa parcela da humanidade. Ao mesmo tempo, com o desaparecimento estrutural de empregos, a formação de grande parcela de profissionais parece perder completamente o sentido (Catani, Oliveira e Dourado, 2001).

Porém, se a massa de desvalidos não é necessária para o mercado, sua insurreição contra o regime, pelas intoleráveis condições de sobrevivência, poderia abalar a ordem. É preciso, então, mantê-los minimamente satisfeitos. Nesse sentido, cabe à saúde executar ações simplificadas ao máximo, porque de menor custo, mesmo que ineficazes para recuperar as condições de funcionamento desses corpos como força de trabalho. Segundo Rizzotto (2005), essa simplificação já estaria ocorrendo em alguma medida no SUS, palco de permanente disputa entre os segmentos que defendem um sistema de saúde universal e aqueles que defendem os interesses rapaces da subordinação da vida e da saúde à lógica do lucro.

A atenção médica aos sobrantes ocorrerá, então, visando prioritariamente o seu controle, e não a sua reprodução; prescinde-se, assim, do cuidado integral, pois tal controle será possível com práticas simplificadas apenas, realizadas por médicos com uma formação também simplificada. Logicamente, essa simplificação é decorrente, também, do avanço inexorável dos meios de produção da própria medicina. No âmbito restrito da produção de serviços médicos, a lógica capitalista, impulsionada pela permanente necessidade de melhora da produtividade, tende a produzir tecnologias que simplificam os processos de trabalho, ao objetivar o conhecimento. O incremento da tecnologia, representado pela utilização de novos equipamentos, protocolos, consensos etc., tende a tornar possível a realização de procedimentos mais eficientes, por trabalhadores menos qualificados.

\section{A formação médica adequada às necessidades sociais}

Desconsiderando o exposto, a atual discussão sobre educação médica no Brasil focaliza o debate na inadequação do processo educativo em referência 
às necessidades sociais. O discurso hegemônico oculta a divisão de classes e apresenta tanto a educação quanto a medicina como setores neutros que responderiam aos interesses de uma sociedade abstrata, entendida como um conjunto de indivíduos unidos pelos mesmos objetivos. E mascara as necessidades do mercado por uma força de trabalho mais barata e flexível como sendo a necessidade da sociedade na atualidade.

O trabalhador tem duas espécies fundamentais de necessidades. Por um lado, necessita manter-se em condições de participar do movimento da humanidade no sentido de criar e ampliar as possibilidades de realização da vida, afastando os limites que a natureza impõe. É a necessidade de participar da produção dos valores de uso. 13 Ao mesmo tempo, tem necessidade de se apropriar dos valores de uso produzidos para, então, constituir-se como expressão singular do gênero humano. Isso significa participar do usufruto dos conhecimentos, alimentos, energia, cuidados à saúde etc. que lhe permitam permanecer vivo pelo maior tempo possível, em condições de máxima realização de suas potencialidades.

O capital, por seu turno, tem como necessidade inarredável a exploração máxima de todos os trabalhadores, sejam operários, artistas, agricultores ou médicos, para extração da mais-valia, substância vital à sua sobrevivência.

A necessidade da classe trabalhadora de participação na produção de valores de uso e de seu livre usufruto é, portanto, oposta àquela da classe capitalista, de produção de valores de troca14 a um custo que limita ao máximo a possibilidade de desfrute pleno dos valores de uso pela classe trabalhadora.

A educação necessária para o capital é aquela que produz, com o menor custo, um trabalhador que se ajusta agilmente às novas tecnologias, que cada vez mais se priva do conhecimento sobre o processo de trabalho - que vem sendo transferido para os meios de produção - e que, portanto, pode ser adestrado rapidamente e sem grandes investimentos para manter o processo produtivo funcionando. O custo da reprodução da força de trabalho também pode ser reduzido, dentre outras maneiras, pela instituição de uma assistência médica simplificada.

É claro que, se para a classe dominante, não interessa gastar parte de seu capital com a reprodução de parcela 'inútil' da população, ou gastar 'desnecessariamente' com a parcela ainda 'útil', a qualidade e a quantidade dos serviços de reprodução da força de trabalho tenderão a se reduzir.

No Brasil, as políticas neoliberais há várias décadas têm marcado a ação do Estado com graves restrições no amparo social que se pretendeu estabelecer na Constituição de 1988. Saúde e educação constituem dois espaços emblemáticos de tal direcionamento, expondo a corrosão de sistemas que se pretendia instituir solidamente na direção da proteção social fundada na ideia da seguridade. 
Se o SUS tem sofrido pressões e desvios no sentido de tornar-se um pacote básico de assistência para os pobres (Bahia, 2011; Rizzotto, 2000 e 2005), a educação, que já não alcançara a integralidade e a universalidade proposta para a saúde, direciona-se agilmente no sentido de atender às necessidades do mercado (Gentili, 1996; Moraes, 2000; Paro, 1999).

A educação no Brasil tem se voltado para a formação mais rápida e superficial, direcionada prioritariamente à solução de problemas do cotidiano, e não necessariamente à apreensão dos conhecimentos produzidos historicamente pela humanidade - conhecimentos esses sintetizados em fundamentos científicos que nos permitem compreender a realidade para além de sua aparência e que são e essenciais para guiar a nossa ação transformadora no sentido da humanização do mundo.

A educação médica, orientada também pelo ideário neoliberal, tem em grande medida atendido às receitas para uma formação mais pragmática e menos onerosa (Albuquerque, 2009). Nesse espaço, é cada vez maior a adoção de pedagogias ditas ativas, que podem ser utilizadas para legitimar a retirada do conteúdo científico, baseada na crítica leviana à imposição de conceitos que seriam transmitidos de forma autoritária ao estudante na educação dita tradicional.

Na formação de um trabalhador flexível, essas pedagogias são bem indicadas, pois permitem adestrá-lo a obedecer aos protocolos, a solucionar pequenos desvios que a produção apresente e adaptá-lo rapidamente, com novo treinamento, às atualizações tecnológicas introduzidas nos processos produtivos.

Na medicina, isso pode significar o triunfo de uma prática heterogerida, guiada por interesses alheios e realizada por médicos meros executores de técnicas. Também na medicina, o avanço tecnológico permite a retirada do conhecimento do trabalhador, utilizando dois tipos distintos de médicos: um grupo, cada vez menor, capaz de desenvolver as tecnologias e outro, cada vez maior, capaz de aprender a consumir e a utilizar essas tecnologias, sem, necessariamente, dominar sua base científica.

\section{Método}

Optou-se pelo método do materialismo histórico-dialético por se entender que ele permite compreender a educação médica como fenômeno social subordinado às condições históricas de produção econômica e, portanto, determinado pelo grau de desenvolvimento das forças produtivas e pelas relações sociais de produção.

Para a análise, realizou-se um estudo de caso, com alunos de medicina, tutores, preceptores e coordenadores de três grupos do PET-Saúde (que passaremos a denominar PET A, PET B e PET C) de duas universidades de Curitiba. 
Após aprovação pelo Comitê de Ética em Pesquisa do Setor de Ciências da Saúde da Universidade Federal do Paraná (UFPR), em reunião realizada no dia 26 de maio de 2010, com registro CEEP/SD 919.044.10.5 e CAAE 0026.0.091.000-10,15 e consentimento dos entrevistados, procedeu-se à coleta de dados por meio de grupos focais ou individualmente, quando a reunião do grupo não era possível, por incompatibilidade de horário. Os coordenadores foram entrevistados separadamente dos alunos, a fim de evitar qualquer constrangimento desses últimos.

As entrevistas seguiram o mesmo roteiro dos grupos focais. Todo material foi gravado, transcrito e posteriormente analisado, buscando-se identificar as atividades de cada grupo na atenção básica, verificar a concepção de educação ou filiação pedagógica e sua contribuição para a formação médica.

\section{Resultados e discussão}

PET A

Composto por estudantes de medicina, tutor médico docente de Saúde Coletiva e preceptores dentistas, enfermeiros e farmacêuticos do SUS que foram deslocados das unidades de saúde (USs) nas quais trabalhavam, pois a gestão municipal não consentiu que desempenhassem a função de tutor durante sua jornada de trabalho.

Esse grupo articulou projetos de pesquisa com a monitoria das disciplinas nas quais estudantes realizam atendimento clínico supervisionado. Cabia aos monitores do PET orientar o Projeto Terapêutico Singular16 (PTS), realizado pelos alunos dessas disciplinas, e desenvolver um projeto de pesquisa, em parceria com a coordenação das USs, com base em suas demandas. Para esse projeto, os alunos desenvolveram previamente, a partir de relatos, levantamento de dados de prontuários, declarações de nascidos vivos e outros registros da USs, um roteiro de observação e um diagnóstico compartilhado. Com base nesses dados, elaboraram projetos de intervenção. Em grupos de dois ou três alunos, sob orientação específica do tutor, realizaram ações de educação em saúde para os adolescentes, curso para cuidadores de idosos e acompanhamento do programa de hipertensos e diabéticos.

A orientação teórica, realizada pelo tutor, constituiu-se inicialmente de uma reflexão sobre o conceito de atenção primária em saúde (APS) e seu papel no sistema de saúde, da leitura de artigos sobre modelos de atenção e diferentes modelos de atenção primária. Segundo os entrevistados, buscou-se

(...) apresentar ao aluno do PET uma noção geral sobre saúde coletiva, a partir de um campo, que é o campo de política, planejamento e gestão, para apoiar o profissio- 
nal de saúde, para que ele possa ir para esse campo e entender o funcionamento do serviço. Enfim, relação com os outros níveis de atenção.

No início da pesquisa, foram feitas reuniões quinzenais de orientação para todos os alunos e orientações específicas para cada subgrupo, dependendo da necessidade. Realizou-se a leitura de alguns textos, mas, segundo os entrevistados, tratava-se de leituras não acompanhadas de discussões de aprofundamento da compreensão, pois visavam fornecer aos alunos um panorama geral sobre os assuntos.

As atividades de pesquisa e intervenção exigiram a utilização do programa Epi Info e do prontuário eletrônico, o que permitiu aos alunos que passassem a conhecê-los. A aquisição de outras informações ou conhecimentos necessários para a realização das atividades dependeu da iniciativa dos próprios alunos.

Tivemos de ler alguns textos no começo, mas, da metade do PET em diante, só falávamos das atividades que estavam sendo desenvolvidas na unidade de saúde durante as reuniões. O resto das coisas, nós é que fomos atrás (Estudante).

Os temas discutidos foram, segundo os entrevistados, práticas de saúde instituídas no serviço clínico da saúde coletiva, clínica ampliada, saúde coletiva ampliada e compartilhada, PTS, trabalho em equipe, corresponsabilização e trabalho coletivo. Houve também, para os grupos menores, orientação quanto à produção de uma pesquisa científica.

A especificidade do trabalho nas USs variou muito, dependendo da dupla de alunos que o realizavam. Todas as duplas, no entanto, coletaram informações dos pacientes visando identificar situações para as quais pudessem elaborar uma proposta de intervenção.

Segundo os estudantes, a elaboração do PTS permitiu conhecer as limitações do SUS e aprender a trabalhar tanto com elas quanto com as condições adversas de vida dos pacientes, adequando as propostas aos limites identificados. Permitiu, também, vivenciar uma relação de corresponsabilidade com o paciente.

As atividades em geral possibilitaram conhecer a estrutura e o processo de trabalho das USs, e suas potencialidades e limitações, bem como aspectos da prática corrente dos serviços. Aproximaram os estudantes do atendimento ambulatorial à morbidade prevalente entre os usuários das USs, o que o ensino hospitalar especializado não tem proporcionado.

Essas atividades estavam fundadas nas concepções pedagógicas da aprendizagem pela solução de problemas, no aprender a aprender - concepções marcadas pelo pragmatismo utilitário e pela busca da formação de um trabalhador apto para resolver os problemas enfrentados no cotidiano 
do trabalho, e que, por isso, não são as mais adequadas em uma educação que vise transmitir às novas gerações o que de mais elevado tenha sido produzido pelo gênero humano no campo do conhecimento. Para Duarte (2004), com a adoção de tais pedagogias, instalou-se

(...) uma mentalidade altamente pragmática, centrada apenas no hoje, no aqui e no agora, criando-se uma aversão àquilo que Saviani (1997, p. 22-23) denominou 'clássico' no saber socialmente produzido, uma aversão ao esforço necessário ao estudo do clássico, uma aversão à teoria considerada como inútil e uma valorização do banal, dos casos pitorescos ocorridos no cotidiano de cada indivíduo, uma valorização do fácil, do útil, do que não exija questionamento, crítica, raciocínio (Duarte, 2004, p. 68).

São concepções de educação que não pretendem do aluno o domínio da base científica de cada área de atuação produzida pelas gerações anteriores da humanidade, mas somente o desempenho técnico apoiado no conhecimento instrumental de última geração.

Cada estudante buscava, quase que exclusivamente, apropriar-se do conhecimento necessário e suficiente apenas para resolver o problema imediato com o qual se defrontava. Isso fica evidente quando os alunos entrevistados destacam como fundamental o fato de aprender a utilizar o programa Epi Info ou o prontuário eletrônico, considerado por eles uma das principais contribuições do projeto para a sua formação.

Nesse caso a educação tem a finalidade de ensinar a busca do conhecimento necessário para a situação, ou seja, 'aprender a aprender'. Sobre isso, Duarte pondera:

'Aprender a aprender' é, na verdade, aprender a buscar, por si mesmo, entre as ofertas do mercado do conhecimento, as informações e os saberes necessários à adaptação a um determinado tipo de atividade (Duarte, 2004, p. 133).

Nas respostas dos alunos sobre contribuição para sua formação e fundamentação teórica, pode-se afirmar que o contato com a realidade foi revelador de uma diferença entre teoria e prática:

Ele [o contato com a realidade] me mostrou uma abordagem prática do que a gente vê na saúde coletiva que eu, apesar de conhecer o conceito, não sabia como era realmente, e o conceito, agora eu vejo que é bem distante do real (Estudante).

No entanto, essa 'nova realidade' não foi questionada em seus nexos com a macroestrutura social, passando a ser aceita, sem críticas, como 'nova verdade'. O conceito distante do real refere-se à diferença observada pelo estu- 
dante entre a concepção do SUS e a concretude dos serviços de saúde. Tal diferença, no entanto, não foi discutida de modo a permitir a compreensão de sua determinação, seja no nível da estrutura de nossa sociedade, seja no nível dos serviços municipais analisados.

A análise que esse grupo fez da realidade encontrada, assim como as intervenções propostas pelas pesquisas realizadas, não buscaram compreender fenômenos estruturais, como as relações de poder e de dominação, ou a estratificação social, enquanto determinantes das situações por eles vivenciadas. O relato de um dos estudantes revela a mera representação da realidade em sua aparência: “Experiência prática, mas que serviu para coisas específicas, serviu para ver como funciona" (Estudante).

As pesquisas visando identificar situações que permitissem a instituição dos PTS explicitaram a centralização nas ações individuais, pretensamente transformadoras da realidade - conceito difundido pelas correntes pós-modernas. 17 Nessa lógica, a mudança necessária para a melhoria da saúde da população compreenderia as iniciativas individuais e poderia ocorrer deixando intocada a estrutura social.

Tal pensamento fundamenta concepções liberais de necessidades de saúde que, segundo Breilh (2006), tomam a necessidade humana como valor relativo que depende de opções individuais e das possibilidades de cada pessoa e sua família para adquiri-las no mercado. Essa ideia fica clara nas seguintes afirmações:

Foi bom ver a limitação do sistema e aprender a trabalhar com isso (Estudante).

Às vezes, nem tudo o que está bem conceituado é aplicado na prática (Estudante).

Temos que ser maleáveis, flexíveis, para nos adaptarmos às condições locais (Estudante).

Nessa linha, o grupo adotou a 'clínica ampliada' e o PTS como instrumentos de mudança e adaptação da prática médica.

Segundo Campos e Amaral (2007), a clínica ampliada propõe a ampliação do olhar do cuidado em saúde, passando da centralidade na doença à centralidade no sujeito e nas situações de seu cotidiano que representam risco ou vulnerabilidade diante dos agravos à saúde. A clínica ampliada pode ser vista, assim, como a 'clínica do sujeito'.

A ampliação refere-se, também, aos objetivos ou à finalidade da clínica, que não se limitariam à realização dos atos tradicionais de cura, prevenção e recuperação, mas incluiriam também a ampliação do grau de autonomia dos usuários do sistema de saúde. 
A ampliação do grau de autonomia pode ser avaliada pelo aumento da capacidade dos usuários compreenderem e atuarem sobre si mesmos e sobre o mundo da vida. O grau de autonomia se mede pela capacidade de autocuidado, de compreensão sobre o processo saúde/enfermidade, pela capacidade de usar o poder e de estabelecer compromisso e contrato com outros (Campos e Amaral, 2007, p. 852).

A clínica ampliada propõe lidar com as dimensões social e subjetiva das pessoas, e não apenas com a dimensão biológica. A ampliação se dá no âmbito da clínica, no âmbito do sujeito e de suas relações mais diretas, e no âmbito singular, pois, embora busque considerar as condições de vida dos sujeitos, faz isso para adequar o tratamento a elas. No entanto, nessa concepção, a compreensão do 'social' é cosmética, já que ela não propõe mudanças nas condições particulares de reprodução dos grupos sociais, mas tão somente a adequação dos cuidados às condições de vida existentes e a busca de uma mudança de comportamento dos sujeitos, com grande ênfase no autocuidado:

Acho que o trabalho que temos feito é uma incursão dentro da clínica, de pensar como podemos repensar a clínica, de produzir uma prática que seja mais centrada nas necessidades apresentadas pelo paciente, pelo usuário, dentro do contexto em que ele vive, e lidar com isso (Estudante).

Os estudantes aprenderam, assim, a trabalhar com as condições dadas. Esforçaram-se para encontrar possíveis soluções dentro dos limites de um SUS subfinanciado e precarizado, com todas as consequências daí advindas. Ao longo do processo desse grupo, os monitores se fizeram menos presentes às atividades e os não bolsistas desligaram-se gradativamente.

\section{PET B}

Composto por estudantes de Medicina, Enfermagem, Fisioterapia e Nutrição, preceptores e tutor. Grupo marcado por dificuldades estruturais, como falta de preceptores, ausência de objetivos bem definidos no início do projeto e evasão de alunos não bolsistas.

A preceptoria foi realizada por enfermeiros do SUS, deslocados das USs nas quais trabalhavam, assim como ocorreu no PET A. A tutoria foi realizada por médico docente da área de Saúde Coletiva.

De início, realizaram-se reuniões para discussão de temas como territorialização, 18 educação em saúde, saúde da família e metodologia científica, visando nivelar o conhecimento dos alunos no campo da saúde coletiva. Afora isso, a fundamentação teórica restringiu-se ao repasse das informações que os alunos utilizariam na prática. 
Nas USs, os estudantes desenvolveram projeto de territorialização e de educação em saúde. A territorialização exigiu, inicialmente, que os alunos percorressem o bairro para entrevistar os informantes-chave, 19 o que lhes permitiu construírem um mapa digital. O projeto de educação em saúde consistiu na formulação de orientações sobre alimentação dos bebês.

Os estudantes realizaram, também, pesquisas sobre pacientes acamados, gripe $\mathrm{H} l \mathrm{Nl}$, alimentação infantil e determinantes ambientais da saúde/doença. Segundo o tutor, as pesquisas objetivavam compreender o significado desses temas para aquela população, a fim de que os alunos conhecessem seu ponto de vista sobre questões relativas à saúde, permitindo melhor adequar suas propostas àquela realidade.

(...) [Queríamos] tentar entender essas pessoas. (...) No trabalho da gripe, por exemplo, era compreender o significado, o que significou essa questão da gripe (Estudante).

Para isso, o grupo utilizou metodologias ditas qualitativas. Nessas, conforme Ludke e André (1986), a base teórica da investigação será estabelecida durante e mediante o processo investigativo, o que confere às pesquisas um caráter fortemente indutivo, sem hipóteses predefinidas e sem uma filiação teórica predeterminada. A afirmação abaixo ilustra esse movimento, embora revele uma possível fragilidade na preparação dos alunos para empreender tal processo:

Nós só ouvíamos que estávamos construindo juntos o PET, que íamos descobrir juntos. E eu só pensava: 'Eu estou perdida; nem eles sabem onde eu estou'. Mas aos poucos, com os estudos, a gente viu que era isso mesmo (Estudante).

O PET B adotou uma pedagogia de caráter construtivista, do desenvolvimento de competências e do aprender a aprender e aprender a fazer, marcada pela busca limitada e utilitária das bases teóricas suficientes apenas para a solução imediata dos problemas enfrentados. A adoção de tais concepções é revelada pelos entrevistados quando afirmam que a "fundamentação teórica não era prioridade".

Na verdade, a gente não ficou muito 'nisso' [apreensão de base teórica]. Foram retomados alguns assuntos como saúde da família, educação em saúde e territorialização voltados mais para a prática (Tutor).

Os alunos responderam, ainda, que o PET proporcionou um aprendizado pautado na realidade, útil apenas para quem fosse atuar na atenção básica. Para Silva (2005), Duarte (2001) e Gadotti (2000), esse tipo de aprendizagem 
no qual o conhecimento teórico não é utilizado na construção de um pensamento abstrato para a compreensão da realidade, não possibilita uma reflexão mais profunda e a extrapolação do saber adquirido para outras circunstâncias. As falas dos alunos sobre o PET ilustram bem essa questão:

Para quem vai atuar nessa área [atenção básica], é uma vivência ímpar (Estudante).

Vai ser importante para quem for lidar com essa população (Estudante).

Não foi indispensável para minha formação como médico no futuro (Estudante).

Caberia comentar, no entanto, que as atividades desse grupo permitiram aos estudantes ampliar sua visão para além da queixa principal dos pacientes, trazendo outros elementos para a compreensão da causalidade das situações mórbidas, contribuindo, de alguma forma, para desfazer preconceitos. No entanto, como já ponderamos, essas reflexões foram insuficientes para a compreensão da determinação estrutural das condições de vida e saúde ali encontradas e para embasar a crítica à ação medicalizadora da realidade, como ilustra o depoimento a seguir:

A parte de você parar para ouvir o paciente, como um todo, aquela história de vir um poliqueixoso e antes você dizia: 'É pitizento!'... Aqui, eles param para ver onde ele está morando, o estado da casa dele. Vamos dar um jeito! Essa criança está com esta queixa, mas às vezes não é só gastrointestinal; talvez ela esteja sofrendo algum abuso. Chama a psicóloga, chama a enfermeira, vamos acionar a rede! (Estudante).

\section{PET C}

Formado por 15 estudantes de Medicina do $4^{\circ}$ ao $9^{\circ}$ períodos (monitores), por estudantes do Internato em Saúde Coletiva ( $10^{\circ}$ período), por um médico docente da área da Saúde Coletiva e preceptores médicos das USs. Os monitores atuavam em apoio aos colegas do internato, avaliando as atividades da US, identificando deficiências e, em conjunto com os internos, com os residentes da Residência Multiprofissional em Saúde da Família e funcionários da US, planejavam, propunham e implantavam as medidas consideradas necessárias.

Os alunos do internato participavam do atendimento médico, sob supervisão do preceptor, e conduziam a análise da estrutura, processo e resultado das atividades programadas da US, orientados pelo tutor em reuniões semanais.

Para a compreensão das práticas, identificação dos problemas e proposição de mudanças visando à melhoria dos serviços, os monitores desen- 
volveram três pesquisas: de avaliação do cuidado ao diabético, no Programa Hiperdia; de avaliação do conhecimento dos diversos segmentos sociais sobre o controle social no SUS; e de avaliação da contribuição do PET para a formação dos estudantes de Medicina.

Semanalmente, os monitores deslocavam-se às USs para observação, coleta de dados, discussões, proposição e implantação de intervenções, e, na universidade, participavam de reuniões de fundamentação teórica com o tutor. Em subgrupos, recebiam, também, orientação do tutor sobre as investigações, o objeto de estudo, a bibliografia e o método de pesquisa.

Nesse grupo, o número de bolsistas e voluntários manteve-se praticamente inalterado durante todo o processo, e a saída e entrada de alunos, em torno de $30 \%$ do total de participantes, foi resultado de mudanças na disponibilidade de horário nas diversas fases do curso.

As ações foram marcadas pela atenção especial dada à fundamentação teórica, requisito para a inserção nas atividades práticas e na elaboração das pesquisas. Segundo os entrevistados, as reflexões, fundamentadas no materialismo histórico-dialético, buscaram a compreensão para além da condição particular de funcionamento da atenção básica em no território estudado, analisando criticamente o SUS e rompendo com a análise encarcerada nos limites impostos pela estrutura social à plena realização da vida e da saúde. A fundamentação teórica não esteve direcionada apenas para a solução imediata dos entraves, mas também para a compreensão do processo histórico e social de sua determinação. Esse grupo conferiu igual ou maior importância à fundamentação teórica recebida em relação às atividades desenvolvidas junto às USs.

Acho que ficou claro que foi o estudo e o embasamento teórico que conferiram sentido à nossa atividade. Não faria sentido a gente estar ali, só (Estudante).

A fundamentação teórica ocorreu ao longo de todo o processo e teve duas grandes frentes: a leitura da tese de Sergio Arouca "O dilema preventivista" (1975) embasou a análise da saúde-doença e da oferta de serviços de saúde como fenômenos sociais, subordinados às condições históricas de produção econômica - e, portanto, determinados pelo grau de desenvolvimento das forças produtivas e pelas relações sociais de produção; e o estudo de trabalhos sobre os temas específicos das pesquisas.

Os alunos afirmaram ser indispensável o contato com o SUS para além das aparências, destacando a importância de compreender como e por que as coisas acontecem de determinado modo; o contato com a US, por si só, não foi percebido como revelador de "como as coisas acontecem na prática":

Por não estarmos participando ali da unidade todo dia, a gente vê com outros olhos e não acha aquilo normal, do cotidiano. A gente vê isso não só porque é de 
fora, mas porque tem esse embasamento. O tipo de discussão que a gente conseguiu desenvolver na universidade não teríamos em nenhum lugar, em nenhuma disciplina (Estudante).

Desse modo, os alunos desse grupo consideraram fundamental a categoria da 'determinação social' para a compreensão da realidade observada. Citando Breilh (2006), ressaltaram sua consistente contribuição para a crítica do 'paradigma do risco' e da multicausalidade.

Breilh (2006) advoga que as teorias do paradigma do risco desconsideram que os vários fatores que apontam como determinantes da doença operam em dimensões distintas da vida social em todo o espectro dos bens materiais e espirituais aos quais cada grupo social tem acesso. Ou seja, ao explicar a determinação da doença não consideram a relação hierárquica que existe entre 'os determinantes' orgânicos a uma dada totalidade.

Os estudantes ressaltaram a importância da compreensão das relações de mútua determinação das instâncias singular, particular e geral da realidade, pois intervenções apenas no âmbito singular não seriam suficientes para mudar tanto o modo de adoecimento da população quanto o modo de cuidar da mesma nos serviços de saúde, e que a ação nas instâncias particular e geral é indispensável para uma real mudança da situação:

É possível você perceber que não são problemas que seriam tão simples de resolver: são questões mais profundas. Você não resolve só ali na unidade, não é uma coisa que você consegue só mudando uma coisinha ou outra ali, alguma coisa sim, mas existem coisas que você não consegue mudar só no âmbito da unidade em si e que pegam outras instâncias e precisariam de uma atuação maior, mais abrangente (Estudante).

Apesar do grande envolvimento com as USs, os alunos foram críticos sobre diversas práticas, por enxergarem suas limitações. Para o grupo, um projeto como o PET, se realizado sem uma preceptoria presente e sem embasamento científico sólido, resulta em mera reprodução das práticas já existentes, ou na sua 'otimização' dentro dos estreitos limites muitas vezes encontrados em nosso sistema de saúde:

Estando lá eu posso presenciar como as coisas acontecem no dia a dia; mas só indo para a unidade, o máximo que eu vou conseguir é reproduzir aquilo que eu estou vendo ali, a prática do dia a dia, a consulta e tudo o mais (Estudante).

Segundo os estudantes, a fundamentação teórica recebida permitiu uma reflexão acerca da realidade observada, contribuindo de maneira decisiva para a sua formação médica: 
Acho que o que mais contribuiu não foi só estar lá, não foi só chegar à unidade de saúde e aí, de repente, veio de uma forma mágica o porquê existia[aquela situação], mas toda uma discussão que a gente fez aqui, teórica, de discutir texto, (...) sempre se questionando (Estudante).

Esse grupo, portanto, tem uma visão divergente da concepção dos grupos anteriores de defesa dos processos cognitivos que subordinam a teoria à experiência prática.

Apresentando o pensamento de Mao, Zizek reafirma a fundamental importância da teoria para o conhecimento das coisas para além de sua aparência, pois o conhecimento lógico difere do conhecimento sensorial. Penetra na essência dos fenômenos, permitindo a compreensão das contradições e das conexões de cada coisa com a totalidade social em que se engendra. 20

Nessa lógica, o indivíduo é entendido como expressão singular do gênero humano, que realizando a sua vida dentro das possibilidades e limites impostos pelas condições particulares de existência de seu grupo social, condições essas também determinadas pelo grau de desenvolvimento e pelo modo de organização da totalidade social a que pertence. Dessa forma, para conhecer o paciente e a sua realidade, não basta descrever minuciosamente seus hábitos e sua visão de mundo, nem fazer a 'territorialização' com a concepção restrita aqui apresentada.

A ideia de territorialização como mera representação da realidade de uma determinada comunidade constitui um reducionismo grotesco, pois propõe a análise de fatos locais sem estabelecer os nexos de determinação com as instâncias de maior generalidade e acaba por introduzir a compreensão equivocada de comunidade como sinônimo de sociedade (Albuquerque, 2009). Para Klein:

Essa compreensão tem derivado da ideia de que a apreensão do sujeito é tanto mais concreta, e, portanto, histórica, quanto mais intenso o esforço de descrever minuciosamente as especificidades do seu ambiente imediato: o lugar onde vive, com quem vive, os usos e costumes da sua gente (...) (Klein, 2002, p. 42).

Para essa autora, ao se excluírem da análise as relações sociais que estão na origem das condições de existência (e, diríamos também, de saúde) das 'comunidades' estudadas, admite-se uma causa interna, uma 'essência' natural a cada fragmento social, tomado como 'realidade' ou totalidade.

\section{Conclusão}

Os três grupos estudados colocaram os estudantes em contato com a atenção básica. Os grupos A e B, no entanto, buscaram adaptar-se às limitações do 
serviço. O grupo C, além de buscar qualificar o trabalho dentro das condições encontradas, procurou evidenciar a gênese dos problemas e refletir sobre os possíveis caminhos para o enfrentamento da situação.

As concepções educativas dos grupos A e B, fundadas nas pedagogias do 'aprender a aprender', contribuem para a formação de trabalhadores flexíveis, efetivos na aplicação da tecnologia para a solução dos problemas, nos limites impostos pela ordem vigente. Já no PET C, a fundamentação com base no materialismo histórico-dialético e o grande investimento no conteúdo científico contribuíram para a formação de sujeitos críticos, capazes de questionar os limites impostos pelo Estado e pela sociedade para a plena realização da vida.

\section{Colaboradores}

Os autores trabalharam juntos em todas as etapas de produção do manuscrito.

\section{Notas}

1 Professor do Departamento de Saúde Comunitária da Universidade Federal do Paraná (UFPR), Alto da Glória, Curitiba, Paraná, Brasil. Doutor em Educação pela Universidade Federal do Paraná (UFPR). <guilherme.albuquerque@ufpr.br>

Correspondência: Universidade Federal do Paraná, Núcleo de Estudos em Saúde Coletiva, Departamento de Saúde Comunitária, Rua Padre Camargo, 280, $7^{\circ}$ andar, Alto da Glória, Curitiba, Paraná, Brasil, CEP 80060-240.

2 Membro do Núcleo de Estudos em Saúde Coletiva da Universidade Federal do Paraná (NESC/UFPR), Alto da Glória, Curitiba, Paraná, Brasil. Graduanda em Medicina pela Universidade Federal do Paraná (UFPR). < ana.revoredo@gmail.com>

3 Médica. Pesquisadora do Núcleo de Estudos em Saúde Coletiva da Universidade Federal do Paraná (NESC/UFPR), Alto da Glória, Curitiba, Paraná, Brasil. $<$ ba_nascimento@hotmail.com>

4 Médica. Pesquisadora do Núcleo de Estudos em Saúde Coletiva da Universidade Federal do Paraná (NESC/UFPR), Alto da Glória, Curitiba, Paraná, Brasil. <biamarela@yahoo.com.br> 
5 Médico. Pesquisador do Núcleo de Estudos em Saúde Coletiva da Universidade Federal do Paraná (NESC/UFPR), Alto da Glória, Curitiba, Paraná, Brasil. $<$ topdiego@ig.com.br>

${ }^{6}$ Membro do Núcleo de Estudos em Saúde Coletiva da Universidade Federal do Paraná (NESC/UFPR), Alto da Glória, Curitiba, Paraná, Brasil. Graduanda em Medicina pela Universidade Federal do Paraná (UFPR). <orlando.juliana@yahoo.com.br>

7 Médico. Pesquisador do Núcleo de Estudos em Saúde Coletiva da Universidade Federal do Paraná (NESC/UFPR), Alto da Glória, Curitiba, Paraná, Brasil. $<$ basso2211@hotmail.com>

8 Professor do Departamento de Enfermagem da Universidade Federal do Paraná (UFPR). Doutorando em Educação pela Universidade Federal de Santa Catarina (UFSC). <perna@ufpr.br>

9 Tal corrente de pensamento tem-se constituído como base ideológica do movimento de tentativa de recomposição do capitalismo diante do agravamento da crise que experimenta (Cavazotti, 2010).

10 Trabalho vivo corresponde àquele realizado com a presença do trabalhador em ato, enquanto trabalho morto é aquele realizado pela máquina, objetivação de um trabalho vivo pretérito (Marx, 1996).

11 Para Marx (1965), o exército industrial de reserva corresponde a uma superpopulação relativa, uma parcela da força de trabalho que excede as necessidades da produção.

12 Frigotto (1999) utiliza o termo sobrante referindo-se à parcela da população que excederia inclusive aquela que configura o exército de reserva. Sobrante, para o autor, "trata-se de contingente não integrado e não integrável ao mundo da produção". Marx (1965) utiliza o termo sobrante como sinônimo de exército industrial de reserva.

13 "A utilidade de uma coisa faz dela um valor de uso. Essa utilidade, porém, não paira no ar. Determinada pelas propriedades do corpo da mercadoria, ela não existe sem o mesmo." (Marx, 1996, p. 166)

14 Valor de troca é "apenas o quantum de trabalho socialmente necessário ou o tempo de trabalho socialmente necessário para a produção de um valor de uso" (Marx, 1996, p. 169).

15 Texto inédito, elaborado a partir de pesquisa realizada por componentes do Núcleo de Estudos em Saúde Coletiva da Universidade Federal do Paraná (NESC/UFPR), linha de pesquisa "Economia política da saúde". Contou com a participação de pesquisadores docentes e discentes (voluntários e bolsistas do PET-Saúde).

16 Projeto terapêutico é uma discussão de caso em equipe, que incorpore a noção interdisciplinar e que recolha a contribuição de várias especialidades e de distintas profissões. Objetiva a revisão do diagnóstico, nova avaliação de riscos e uma redefinição das linhas de intervenção terapêutica, redefinindo tarefas e encargos dos vários especialistas. Trata-se de uma ferramenta da clínica ampliada visando à singularização do atendimento clínico, à maior autonomia do paciente e à potencialização do autocuidado (Campos e Amaral, 2007, p. 853) . 
$17 \mathrm{O}$ pensamento pós-moderno desqualifica as metanarrativas, a ideia da determinação social, a historicidade. Para os pós-modernos, não há uma história única que determina as diferenças sociais, uma história socialmente determinada, mas inúmeras histórias particulares, locais, descontínuas - as histórias de indivíduos e grupos -, o que impede a apreensão do real como totalidade. E, se não há leis gerais que expliquem e determinem as desiguais condições de existência, a desigualdade é naturalizada, uma vez que resultaria das diferenças de atitudes, desejos e capacidades de cada indivíduo (Cavazotti, 2010).

18 Termo utilizado pelos entrevistados com a conotação mais corrente na saúde pública, sendo entendido, basicamente, como ferramenta para reconhecer e esquadrinhar o território segundo a lógica das relações entre ambiente, condições de vida, situação de saúde e acesso às ações e serviços de saúde (Teixeira, Paim e Villasbôas, 1998), incluindo a localização de eventos de saúde-doença e de unidades de saúde e a demarcação de áreas de atuação (Souza, 2004).

19 Membro da comunidade que tem grande conhecimento da cultura estudada e que compreende o papel do pesquisador enquanto um aprendiz cultural (Spradley, 1979).

20 A verdadeira tarefa do conhecimento consiste em chegar, passando pelas sensações, ao pensamento, em chegar passo a passo à compreensão das contradições internas das coisas objetivas, de suas leis e das conexões internas entre um processo e outro, quer dizer, em chegar ao conhecimento lógico. Repetimos: o conhecimento lógico difere do conhecimento sensorial, pois esse concerne aos aspectos isolados, às aparências e às conexões externas das coisas, enquanto aquele, dando um grande passo adiante, alcança o conjunto, a essência e as conexões internas das coisas, põe a descoberto as contradições internas do mundo circundante e, por conseguinte, pode chegar a dominar o desenvolvimento do mundo circundante em seu conjunto, nas conexões internas de todos os seus aspectos (Zizek, 2010, p. 84).

\section{Referências}

ALBUQUERQUE, Guilherme S. C. As determinações do capital sobre a formação do trabalhador na saúde: um estudo sobre reformulações curriculares em dois cursos de medicina do Paraná. 2009. 249f. Tese (Doutorado em Educação) - Programa de Pós-graduação em Educação, Universidade Federal do Paraná, Curitiba, 2009.

ALVES, Gilberto L. A produção da escola pública contemporânea. Campinas: Faculdade de Educação da Unicamp, 1998.
AROUCA, Antônio S. da S. O dilema preventivista: contribuição para a compreensão e crítica da medicina preventiva. 1975. 197f. Tese (Doutorado em Medicina Social) - Faculdade de Ciências Médicas, Universidade Estadual de Campinas, Campinas, 1975.

BAHIA, Ligia. A privatização no sistema de saúde brasileiro nos anos 2000: tendências e justificação. In: SANTOS, Nelson R.; AMARANTE, Paulo D. C. (Org.). Gestão pública e relação público privado na saúde. Rio de Janeiro: Cebes, 2011. p. 115-128. 
BRASIL. Conselho Nacional de Educação. Câmara de Educação Superior. Resolução CNES/CES n. 4/2001. Diário Oficial da União, Brasília, DF, seção 1, p. 38, nov. 2001.

BRASIL. Ministério da Saúde. Mais saúde: direito de todos: 2008-2011. 2. ed. Brasília: Ministério da Saúde, 2008. Disponível em: $<$ http://bvsms.saude.gov.br/bvs/pacsaude/ pdf/mais_saude_direito_todos_2ed_p6.pdf $>$. Acesso em: 1 ago. 2011.

BREILH, Jaime. Epidemiologia crítica: ciência emancipadora e interculturalidade. Rio de Janeiro: Editora Fiocruz, 2006.

CAMPOS, Gastão W. S.; AMARAL, Marcia A. A clínica ampliada e compartilhada, a gestão democrática e redes de atenção como referenciais teórico-operacionais para a reforma do hospital. Ciência \& Saúde Coletiva, Rio de Janeiro, v. 12, n. 4, p. 849-859, jul./ago. 2007.

CATANI, Afrânio M.; OLIVEIRA, João F.; DOURADO, Luiz F. Política educacional, mudanças no mundo do trabalho e reforma curricular nos cursos de graduação no Brasil. Educação \& Sociedade, São Paulo, v. 22 , n. 75 , ago. 2001.

CAVAZOTTI, Maria A. Educação e conhecimento científico: inflexões pós-modernas. Campinas: Autores Associados, 2010.

CHAUÍ, Marilena S. Uma ideologia perversa. Folha de S. Paulo, São Paulo, 14 mar. 1999. Disponível em: <wwwl.folha.uol. com.br/fol/brasil500/dc_1_4.htm>. Acesso em: 26 mar. 2013.

DONNANGELO, Maria C. F.; PEREIRA, Luiz. Saúde e sociedade. São Paulo: Duas Cidades, 1976.

DUARTE, Newton. As pedagogias do 'aprender a aprender' e algumas ilusões da assim chamada sociedade do conhecimento. Revista Brasileira de Educação, São Paulo, n. 18, p. 35-40, set./dez. 2001.
Conhecimento tácito e conhecimento escolar na formação de professor: por que Donald Schön não entendeu Luria. Educação \& Sociedade, Campinas, v. 24 , n. 83, p. 601-625, ago. 2003.

. Vigotski e o 'aprender a aprender': crítica às apropriações neoliberais e pós-modernas da teoria vigotskiana. 3. ed. Campinas: Autores Associados, 2004.

FINI, Maria I. Sobre a pesquisa qualitativa em educação, que tem a fenomenologia como suporte. In: BICUDO, Maria A. V.; ESPÓSITO, Vitória H. C. (Org.). Pesquisa qualitativa em educação: um enfoque fenomenológico. Piracicaba: Editora Unimep, 1997. p. 23-33.

FRIGOTTO, Gaudêncio. Globalização e crise do emprego: mistificações e perspectivas da formação técnico-profissional. Boletim Técnico do Senac, Rio de Janeiro, v. 25, n. 2, maio/ago. 1999.

GADOTTI, Moacir. Perspectivas atuais da educação. São Paulo em Perspectiva, São Paulo, v. 14, n. 2, p. 3-11, abr./jun. 2000.

GENTILI, Pablo. Neoliberalismo e educação: manual do usuário. In: SILVA, Tomaz Tadeu da; GENTILI, Pablo (Org.). Escola $S . A$.: quem ganha e quem perde no mercado educacional do neoliberalismo. Brasília: CNTE, 1996. p. 9-49.

KLEIN, Lígia R. Alfabetização: quem tem medo de ensinar?. 4. ed. São Paulo; Campo Grande: Cortez; Editora da Universidade de Mato Grosso do Sul, 2002.

LUDKE, Menga; ANDRÉ, Marli E. A. Pesquisa em educação: abordagens qualitativas. São Paulo: EPU, 1986.

MARX, Karl. El capital. La Habana (Cuba): Venceremos, 1965.

O capital: crítica da economia política. São Paulo: Nova Cultural, 1996. (volume 1, tomo 1). 
; ENGELS, Friedrich. Manifesto do Partido Comunista. São Paulo: Martin Claret, 2005.

MORAES, Reginaldo C. As incomparáveis virtudes do mercado: políticas sociais e padrões de atuação do Estado nos marcos do neoliberalismo. In: KRAWCZYK, Nora; CAMPOS, Maria M.; HADDAD, Sérgio (Org.). O cenário educacional latino-americano no limiar do século XXI: reformas em debate. Campinas: Papirus, 2000. P.13-42.

PARO, Vitor H. Parem de preparar para o trabalho!!! Reflexões acerca dos efeitos do neoliberalismo sobre a gestão e o papel da escola básica. In: FERRETTI, Celso J.; SILVA JUNIOR, João R.; OLIVEIRA, Maria R.N.S. Trabalho, formação e currículo: para onde vai a escola? São Paulo: Xamã, 1999. P.101-120.

RIZZOTTO, Maria L. F. As propostas do Banco Mundial para as reformas de saúde no Brasil nos anos 90. Saúde em Debate, Rio de Janeiro, v. 29, n. 70, p. 140-147, maio/ago. 2005.

- O Banco Mundial e as politicas de saúde no Brasil nos anos 90: um projeto de desmonte do SUS. 2000. Tese (Doutorado em Saúde Coletiva) - Faculdade de Ciências Médicas, Universidade Estadual de Campinas, Campinas, 2000.
SILVA, João C. Educação e alienação em Marx: contribuições teórico-metodológicas para pensar a história da educação. Revista HISTEDBR [online], São Paulo, n. 19, p. 101-110, set. 2005 .

SOUZA, Maria A. A. de. Uso do território e saúde. Refletindo sobre "municípios saudáveis". In: SPERANDIO, Ana M. G. (Org.). o processo de construção da rede de municípios potencialmente saudáveis. Campinas: Ipes Editorial, 2003. (volume, 1). P. 57-77.

SPRADLEY, James. The Ethnographic Interview. Nova York: Holt Rinehart \& Winston, 1979.

TEIXEIRA, Carmem F.; PAIM, Jairnilson S.; VILLASBÔAS, Ana L. SUS, modelos assistenciais e vigilância da saúde. Informe Epidemiológico do SUS, v. 7, n. 2, p.7-28, 1998.

ZIZEK, Slavoj. Sobre la práctica y la contradicción: Slavoj Zizek presenta a Mao. Madri: Akal, 2010.

Recebido em 27/04/2012

Aprovado em 10/10/2012 